\title{
ALTERAÇÕES BUCAIS E CONDUTAS TERAPÊUTICAS EM PACIENTES INFANTO-JUVENIS SUBMETIDOS A TRATAMENTOS ANTI-NEOPLÁSICOS*
}

\section{ORAL ALTERATIONS IN JUVENILE PATIENTS SUBMITTED TO RADIOTHERAPY AND CHEMOTHERAPY*}

\author{
Fernanda Maria Kroetz ${ }^{1}$ e Gislaine Denise Czlusniak ${ }^{2}$
}

1 Autor para contato: Rua Petit Carneiro, 1331 - apto. 1401, Curitiba, PR, Brasil;

(41) 343-0274; e-mail: ferkroetz@brturbo.com

2 Universidade Estadual de Ponta Grossa - UEPG, Departamento de Odontologia; Curso de Especialização em Odontopediatria da EAP/ABO-Ponta Grossa;

(42) 220-3111; e-mail:czlusniak@uol.com.br

Recebido para publicação em 01/09/2003

Aceito para publicação em 22/10/2003

\section{RESUMO}

Entre as doenças malignas na infância, a leucemia é a mais comumente encontrada, sendo caracterizada pela produção descontrolada de blastos, ou seja, leucócitos na forma imatura. Apresenta várias manifestações clínicas, como febre, sintomatologia dolorosa nos ossos e articulações, fadiga, mal-estar, além de petéquias, equimoses e epistaxes. Na cavidade bucal observam-se quadros clínicos de gengivites, hiperplasias gengivais, infecções oportunistas, alterações radiográficas nos ossos alveolares e sangramentos gengivais espontâneos. Durante o tratamento antineoplásico,as alterações na cavidade bucal alcançam maior gravidade, pois tanto a radioterapia quanto a quimioterapia não diferenciam as células neoplásicas das células normais. Como conseqüência, provocam mucosite, xerostomia, infecções fúngicas, bacterianas e virais, além de alterações no paladar e ligamento periodontal. Hemorragias gengivais, distúrbios na formação dos germes dentários, trismo muscular, cárie de radiação e osteorradionecrose são achados com freqüência. Dessa forma, há necessidade do estabelecimento de um protocolo no atendimento odontológico que abranja diversas medidas profiláticas, adequando a cavidade bucal antes de iniciar as terapias anti-neoplásicas, com a finalidade de melhorar a qualidade de vida do paciente infantil.

Palavras-chave: leucemia; quimioterapia; radioterapia; protocolo de atendimento odontológico.

\footnotetext{
*Artigo referente à monografia apresentada no curso de Especialização em Odontopediatria da EAP/ ABO de Ponta Grossa.
} 


\begin{abstract}
Among the malignant diseases that affect infancy, leukemia is the most common and is characterized by the uncontrolled production of leucocytes in their immature blast form. Fever, pain in the bones and bony articulations, tiredness, malaise and bleedings are clinical manifestations of the desease. In respect to buccal findings, gengivitis, gengival hyperplasia, opportunist infections and radiographic detectable bone alterations are frequently observed. During the anti-neoplasic treatment, buccal alterations reach their peak because radiotherapy and also chemotherapy affect both normal and sick cells. As a consequence, various problems can occur, such as: mucositis, xerostomia, fungal, viral and bacterial infections, alterations on taste perception, changes on the periodontium ligament, gingival haemorrage, disturbances on teeth formation, muscular trismus, radiation caries and osteorradionecrosis. The therapeutic treatment protocol requires prophylatic steps before the initiation of radio and chemotherapy, including the treatment of cavitated teeth and the removal of abcessed teeth, if present, in order to contributed to the patient's well-being.
\end{abstract}

Key words: leukemia; chemotherapy; radiotherapy; therapeutic treatment protocol

\section{Introdução}

Câncer é o nome dado a um conjunto de mais de cem doenças que tem em comum o crescimento desordenado (maligno) de células que invadem tecidos e órgãos, podendo espalhar-se (metástase) para outras regiões do corpo. Dividindo-se rapidamente, essas células tendem a ser muito agressivas e incontroláveis, determinando a formação de tumores ou neoplasias malignas. Os diferentes tipos de câncer correspondem aos vários tipos de células do corpo, ou seja, o câncer que se inicia em tecido epitelial é chamado de carcinoma e em tecido conjuntivo como osso, músculo ou cartilagem, denomina-se sarcoma. Pode ser também um tumor líquido como é o caso das leucemias (Ministério da Saúde, 2003).

O tratamento de câncer na infância está sendo promissor nestas duas últimas décadas. Atualmente, $70 \%$ das crianças acometidas por câncer podem ser curadas, se diagnosticadas precocemente e tratadas em centros especializados.As neoplasias mais freqüentes na infância são as leucemias (alterações nos glóbulos brancos), tumores do sistema nervoso central e linfomas (Ministério da Saúde, 2003).

Quanto à epidemiologia, tem-se verificado um aumento progressivo e também linear das taxas de incidência dos tumores na criança, sobretudo a leucemia linfóide aguda, os tumores do sistema nervoso central, os linfomas não Hodgkin e o tumor de Wilms. É importante salientar que de 10 a 15 casos de câncer no Brasil, quatro são de leucemia linfóide aguda. Segundo Lopes et al. (2000), do total de crianças portadoras de neoplasia maligna, 30\% normalmente apresentam leucemia. Devido a esse grande número de casos, o objetivo deste texto é o de conhecer as complicações bucais provenientes do tratamento da leucemia e as maneiras de que dispomos para melhorar a qualidade de vida do paciente durante e após o tratamento.

\section{Revisão de literatura}

A leucemia é uma doença maligna dos glóbulos brancos (leucócitos), de origem na maioria das vezes não conhecida, porém existem alguns indícios de que ela esteja relacionada a alguns fatores ambientais, hereditários e bacteriológicos. (Sonis et al., 1996). Tem como principal característica o acúmulo de células jovens anormais na medula óssea, que substituem as células sanguíneas normais 
(Dobbin, 2001). Essas células, que na medula óssea normal têm funções muito específicas, dando origem às linhagens hematológicas, perdem sua função e o seu relacionamento ecológico no micro ambiente medular. Sua proliferação desordenada e vitoriosamente competitiva termina por substituir toda a linhagem nobre da medula óssea, com diminuição da produção de eritrócitos, ou glóbulos vermelhos (eritropoese), leucócitos (leucopoese) e plaquetas (trombocitopoese). Logo após a invasão medular, os elementos blásticos (células anormais de forma primitiva e indiferenciada) ganham o sangue circulante, onde vão exteriorizar a configuração leucêmica do hemograma. Distribuídas pelo sangue, as células blásticas invadem todo o organismo, iniciando pelos gânglios, baço e fígado, que fazem parte das estruturas hematopoiéticas (Carvalho citado por Maeda, 1998 ). A maioria dos sinais e sintomas relacionados à leucemia derivam-se do fato de que a medula óssea encontra-se repleta de células malignas que passam para a circulação (Sonis et al., 1996).

Na leucemia aguda, segundo Robbins et al., (1986), são observados alguns sinais e sintomas como fadiga, mal estar, anorexia, irritabilidade, febre baixa, sangramentos (petéquias, equimoses, epistaxes e sangramentos gengivais), além de neutropenia.

Como a leucemia é uma doença que atinge o sistema hematopoiético, com comprometimento da medula óssea, as alterações bucais podem ocorrer com freqüência, principalmente na mandíbula, devido a sua grande vascularização. As alterações radiográficas no esqueleto podem ser encontradas em até $50 \%$ dos pacientes. O uso da radiografia panorâmica em crianças com leucemia aguda normalmente indica alterações no desenvolvimento das criptas dentárias, destruição da lâmina dura, deslocamento dos dentes e pouca definição radiográfica do osso alveolar. As primeiras manifestações são encontradas nas áreas de molares e na parte apical do osso alveolar. A grande correlação entre evidências clínicas de leucemia, demonstra que essa radiografia é de grande valor no diagnóstico, principalmente nos casos de reincidência (Curtis, citado por Maeda,1998, p.14)

Segundo Shafer et al. (1987), em crianças portadoras de leucemia, é menos freqüente o aparecimento de manifestações bucais, entretanto é possível verificar-se a presença de gengivite, hiperplasia gengival, hemorragia, petéquias e ulcerações na mucosa. Também podem aparecer lesões púrpuras na mucosa bucal, semelhantes a equimoses cutâneas. A hemorragia gengival é decorrente da ulceração do epitélio do sulco e da necrose do tecido subjacente. Como a distribuição dos leucócitos está muito alterada, torna-se impossível uma resposta inflamatória, mesmo às pequenas infecções. Conseqüentemente, são visíveis as ulcerações avançadas na mucosa bucal, sendo que a trombose dos vasos gengivais acaba contribuindo para esse fenômeno. Devido à neutropenia, esses pacientes estão susceptíveis às infecções virais, bacterianas e fúngicas (Mc Kenna, 2000).

Em pacientes que já sejam portadores de doença periodontal, somando a baixa imunidade, é evidente que a ulceração do epitélio do sulco não é mais controlada pelos mecanismos de defesa, surgindo como conseqüência, a gengivite ulcerativa necrosante aguda (GUNA). A ulceração bucal em pacientes com neutropenia é uma ameaça à vida pois pode servir de porta de entrada para bactérias, evoluindo para uma septicemia. O sangramento gengival espontâneo só ocorrerá quando a contagem de plaquetas, que normalmente deve estar entre 150.000 a 400.000 células $/ \mathrm{mm}^{3}$, estiver inferior a 20.000 células $/ \mathrm{mm}^{3}$, sendo que a contagem de plaquetas inferior a 100.000 células $/ \mathrm{mm}^{3}$ pode resultar em sangramento pós-operatório prolongado (Sonis et al., 1996).

O tratamento de todas as formas de leucemia é realizado pela quimioterapia, em três fases terapêuticas: indução, consolidação ou intensificação e manutenção. No tratamento de indução são administradas altas doses de agentes anti-neoplásicos, com o objetivo de promover a rápida morte das células leucêmicas. É justamente nessa fase que incide a maior quantidade de efeitos secundários com manifestações bucais (mucosite, xerostomia e gengivorragia). A resposta à terapia é dada entre quatro a seis semanas, o que traduz o prognóstico da doença. A consolidação ou intensificação é designada para matar células leucêmicas residuais, as quais podem persistir em número significativo após 
a indução. Essa fase é de curta duração, porém muito intensa na concentração ou combinação das drogas utilizadas. Na fase de manutenção é esperada a completa remissão da doença, a qual é comprovada através de exames de aspiração da medula óssea (mielograma), revelando menos de 5\% de células imaturas e nenhuma evidência clínica da leucemia ,uma avaliação detalhada é realizada 6 a 12 vezes por ano (Sonis et al., 1996).

\section{Tratamento das alterações bucais}

Atualmente são adotadas três modalidades principais de tratamento dos neoplasmas malignos: cirurgia, radioterapia e quimioterapia. Somente a cirurgia é específica para o tecido. A quimioterapia e a radioterapia atuam pela destruição ou pela inibição do crescimento das células que se multiplicam rapidamente, não diferenciando as células neoplásicas das células normais. Conseqüentemente, essas duas terapias produzem vários efeitos colaterais que irão se manifestar também na cavidade bucal (Sonis et al., 1996).

Os efeitos biológicos da radioterapia são localizados somente na área irradiada, sendo que infelizmente essas alterações podem ser permanentes nos tecidos. Os efeitos biológicos da quimioterapia são reversíveis, acontecendo somente durante os períodos de mielo e imunossupressão (Fleming,1991).

$\mathrm{Na}$ cavidade bucal os principais efeitos colaterais da quimioterapia são a mucosite, xerostomia temporária e imunodepressão, possibilitando infecções dentárias ou oportunistas. Observam-se também hemorragias gengivais decorrentes da plaquetopenia e distúrbios na formação dos germes dentários quando administrada na fase de odontogênese (Rey et al.,1994; Minicucci et al.,1994; Fonseca, 1998).

A mucosite é uma inflamação e ulceração da mucosa, freqüente e dolorosa, aparecendo de 3 a 7 dias após o início da quimioterapia e pode durar vários dias. Seu primeiro sinal é a presença de eritema no palato mole, mucosa bucal, ventre de língua e assoalho bucal, seguido de edema e ulceração. Dor, queimação e desconforto estão comu- mente presentes, sendo intensificados durante a alimentação. Sugere-se bochecho com gel de lidocaína, trinta minutos antes das refeições, para minimizar a sintomatologia dolorosa (Dreinzen, 1991). Todo enxaguatório que contiver álcool ou fenol é contraindicado, pois provoca descamação e irritação da mucosa. Pode ser realizado bochecho com solução salina de bicarbonato de sódio (1 colher de sopa em $1 / 4$ copo com água) (Dib et al., 2000). A terapia com laser tópico, assim como a crioterapia bucal (cubos de gelo para vasoconstrição), têm-se mostrado eficazes no tratamento da mucosite (Karthaus et al., 1999).

A xerostomia na quimioterapia é uma alteração transitória no funcionamento das glândulas salivares, cessando logo após o término do tratamento. Quanto à radioterapia, ocorre um comprometimento do parênquima glandular e a xerostomia poderá tornar-se permanente (Cabrerizo et al.,1998). A saliva fica espessa e viscosa, prejudicando a mastigação, a fala e o paladar. Dessa forma, a mucosa bucal estará susceptível à colonização de microorganismos oportunistas (Fonseca, 1998). Observase também uma mudança qualitativa da saliva, que diminuindo sua capacidade tampão (Dib et al., 2000), propicia o desenvolvimento de uma microbiota altamente cariogênica, em decorrência das alterações nos padrões de consumo alimentar com refeições mais freqüentes, mais fáceis de engolir, não detergentes e ricas em carboidratos (purês, sopas, gemadas, gelatinas e pudins). As alterações microbianas, químicas, imunológicas e dietéticas favorecem um grande aumento na atividade cariogênica (Dreizen, 1991). Como alternativa, o fluxo salivar poderá ser estimulado pela ingestão de gomas de mascar e drops de limão, ambos sem açúcar. Poderão também ser usados substitutos de saliva e sialogogos, paliativos estes que aliviam temporariamente o desconforto (Dib et al., 2000). A saliva artificial é um lubrificante formulado a partir de rinses bucais à base de carboximetilcelulose, disponíveis na forma de gel e spray, com a finalidade de reduzir a tensão superficial, lubrificar e hidratar a mucosa bucal, possibilitando ao paciente sensação de conforto.

Os sialogogos são medicamentos administrados via oral, que aumentam farmacologicamente a 
produção de saliva e estimulam o tecido glandular intacto responsivo, restaurando o fluxo salivar normal. A prilocarpina e, recentemente, a amifostine, são as únicas drogas aprovadas pelo "United States Food and Drugs Administration" para uso como sialogogo (Dib et al., 2000).

Enquanto a mucosa de indivíduos normais suporta prontamente os traumatismos de rotina, a quimioterapia predispõe à desintegração da mucosa, à ulceração e à infecção secundária. A Candida albicans é o microorganismo mais freqüente nas infecções bucais de pacientes submetidos à quimioterapia. Dib et al. (2000), recomendam o uso do miconazol gel a 2\% aplicado na boca ou comissuras labiais, quatro vezes ao dia. Segundo Sonis et al. (1996), a solução de nistatina a 400.000 Ui deve ser bochechada quatro vezes ao dia, e em seguida, deglutida. A nistatina também pode ser encontrada em pastilhas, prolongando seu efeito sobre a mucosa bucal.

As infecções pelo vírus herpes simples, podem ocorrer durante a mielossupressão e são tratadas com aciclovir em creme, comprimido ou pó liofilizado para infusão (Sonis et al., 1996 ).

As manifestações bucais da trombocitopenia são ecmozes, petéquias e púrpuras, agravadas ainda mais pela presença de fatores irritantes (bio-filme, cálculo, bandas ortodônticas, brackets, p.ex;). As terapias tópicas, com compressão da área sangrante com gelo e agentes hemostáticos tópicos (esponjas de trombina, microfibrila de colágeno e epinefrina), são considerados como primeira escolha no tratamento. Se o sangramento não cessar e tornar-se mais severo, é indicada uma transfusão de plaquetas. Essa trombocitopenia torna-se um problema também em crianças que estão fazendo troca de dentição. Se possível, esses dentes devem ser extraídos antes de iniciar-se a terapia anti-neoplásica, o que corresponde a dez dias antes do início da neutropenia. Somente os procedimentos conservadores e de urgência devem ser realizados nos períodos de neutropenia, sempre com antibioticoterapia (Chin, 1998).

As alterações dentárias decorrentes da quimioterapia na fase de odontogênese (crianças de até 5 anos de idade), promovem encurtamento radicular em pré-molares, raízes conóides em molares, pré- molares ou caninos, coroas pequenas, hipoplasia e hipocalcificação de esmalte ( Minicucci et al., 1994).

A radioterapia tem a finalidade de exterminar células neoplásicas para que haja redução ou desaparecimento da neoplasia maligna. Entretanto, o efeito dessa terapia produz alterações negativas, no que tange a qualidade de vida dos pacientes durante e após o tratamento (Caielli et al., 1995). Os efeitos colaterais da radioterapia estão relacionados diretamente com a área a ser irradiada. Se a radiação atingir a região de cabeça e pescoço, haverá xerostomia, mucosite, alterações no paladar, disfagia, trismo muscular, alterações no ligamento periodontal, cárie de radiação e osteorradionecrose - Além disso, se o tratamento radioterápico for realizado em crianças durante os seus picos de crescimento (desde o nascimento até a puberdade), também surgirão alterações no crescimento ósseo e no desenvolvimento da dentição (Caielli et al., 1995).

As alterações no paladar ocorrem como resultado direto da radiação nos corpúsculos gustativos e na disfagia, dificultando a mastigação e a deglutição. A redução do fluxo salivar diminui a umidificação dos alimentos, enquanto que a irritação da mucosa faz com que a mastigação seja dolorosa. ( Caielli et al., 1995).

O trismo muscular é a abertura limitada da boca como resultado do edema, destruição celular e fibrose do tecido muscular, induzida pela radiação. O grau do trismo depende da dose de radiação, impossibilitando uma correta higiene bucal (Caielli et al., 1995).

A cárie de radiação é uma forma de cárie rampante, onde as lesões são defeitos superficiais generalizados que afetam superfícies geralmente resistentes à cárie, como superfícies lisas, região cervical e pontas de cúspides (Caielli et al., 1995). Pacientes que possuíam baixa atividade de cárie podem começar a apresentá-la em vários níveis de destruição dental após a radioterapia (Silverman, 1990). Segundo Silverman (1990), a diminuição da saliva é um fator importante no aparecimento e progressão das cáries de radiação, pois a capacidade tampão está severamente reduzida, propiciando desmineralização substancial dos tecidos dentais. Nesse processo de redução do fluxo salivar, há aumento de Streptococos mutans, Lactobacillus, 
Candida e Staphylococcus e ao mesmo tempo, diminuição de Streptococos sanguis e espécies de Neisseria e Fusobacterium. Na microbiota anaeróbica há o aumento de Actinomyces e Veilonella. Clinicamente, a cárie dentária inicia-se na região cervical dos dentes, progredindo superficialmente em torno do colo do dente, e sendo uma lesão circunferencial na junção amelocementária, pode provocar amputação coronária (Caielli et al., 1995).

A osteorradionecrose é a mais severa complicação da radioterapia e ocorre quando os tecidos moles que recobrem o osso são rompidos, devido a irritações locais como prótese ou extração dentária A radiação ionizante restringe o fluxo de sangue na região irradiada, deixando o osso com capacidade mínima de resistir a trauma,e conseqüentemente, mais susceptível à infecção (Caielli et al., 1995).

Quanto menor for o trauma durante a exodontia, menor o risco de osteorradionecrose. Por isso, é improvável que a exfoliação de dentes decíduos provoque esse tipo de alteração. Antes do início da radioterapia todos os dentes extensamente cariados devem ser removidos com pelo menos sete a dez dias de antecedência, para que haja um período de cicatrização (Clayman, 1997).

\section{Protocolo de atendimento odontológico}

As manifestações bucais advindas do tratamento anti-neoplásico, seja com radioterapia ou quimioterapia, são previsíveis. Portanto, o preparo bucal e as orientações dadas previamente aos pais reduzem o índice de complicações. Os responsáveis devem ser orientados sobre como proceder a higiene bucal, pois a presença de placa bacteriana aumenta a severidade da mucosite, além de predispor à inflamação gengival, que pode gerar sangramentos espontâneos, em função de uma possível plaquetopenia. A orientação sobre a dieta cariogência é fundamental. Muitas crianças voltam a se alimentar através de mamadeiras, por inapetência, dificuldade de deglutir, ou até mesmo devido a regressões emocionais. Segundo Dib et al. (2000), a primeira orientação é eliminar o uso da mamadeira, contendo produtos com açúcar. Se os pais estiverem com dificuldade, substitui-se gradativamente os componentes açucarados até chegar simplesmente a água. Segundo o National Institute of Health (NIH) (1989), existe um protocolo de avaliação bucal pré-terapia anti-neoplásica, que consiste em identificar os fatores de risco ao desenvolvimento de complicações bucais, tais como: má higiene bucal, infecções na região de molares, infecções periapicais, doença periodontal, cáries, restaurações com defeito, próteses mal adaptadas, dispositivos ortodônticos e outras fontes potenciais de irritação. Com a finalidade de iniciar-se o mais rapidamente possível a quimioterapia e/ou a radioterapia, sem risco de infecção, deve-se realizar o tratamento odontológico urgencial, que segundo Ribeiro et al. (1997), consiste em:

- remoção de focos infecciosos através de exodontias, tratamentos endodônticos e escavação em massa (curetagem de lesões cariosas e selamento provisório com óxido de zinco e eugenol ou ionômero de vidro), obtendo-se desta forma uma adequação do meio bucal;

- realização de profilaxia dental antes do início da radioterapia e quimioterapia;

- aplicações tópicas de flúor em pacientes que serão submetidos à radioterapia, sendo que nos casos de irritações da mucosa, é indicado o flúor neutro a 0,5 ou 1\% (Dib et al., 1997).

- podem ser realizados bochechos com clorexidina a $0,12 \%$ por ser um potente agente anti-microbiano, porém muitos pacientes não toleram o alto teor alcoólico e o sabor desagradável. Como alternativa, existe a possibilidade da manipulação deste medicamento em veículo não alcoólico.

- o creme dental Oral Balance ${ }^{\circledR}$ da Biotene, segundo especificações do fabricante, contém xylitol que inibe o crescimento de bactérias patogênicas, enzimas que ajudam a estabilizar o meio bucal e não contém lauril sulfato de sódio, que pode causar irritação em mucosas sensíveis.

Sonis et al. (1997), elaboraram um protocolo clínico para prevenir as complicações bucais, dan- 
do as seguintes orientações:

- profilaxia , raspagem e polimento radicular; instruções de higiene bucal; dieta pobre em sacarose; prescrever bochechos com soluções fluoretadas; confeccionar moldeiras individuais para o tratamento caseiro com fluoreto; prescrever gel de fluoreto para uso diário nas moldeiras (preferencialmente neutro); eliminar as cáries ativas; reparar ou eliminar todas as fontes potenciais de irritação e/ou cúspides agudas, fraturadas, grampos quebrados, próteses mal adaptadas ou bandas ortodônticas; exame e profilaxia freqüentes (a cada seis ou oito semanas), com restauração de cáries incipientes, quando necessário; manter o protocolo por pelo menos 12 meses após a radioterapia.

Ainda, segundo esses autores, no paciente com xerostomia, a aplicação diária de um gel fluoretado, suplementado por bochechos, torna-se necessária.

\section{Considerações finais}

Em decorrência da radioterapia e da quimioterapia, várias alterações na cavidade bucal podem ser observadas, entre elas, mucosite, xerostomia, infecções dentárias ou oportunistas, hemorragias gengivais, distúrbios na formação dos germes dentários, alterações no paladar, disfagia, trismo muscular, alterações no ligamento periodontal, cárie de radiação e osteorradionecrose.

Essas complicações bucais podem ser evitadas ou minimizadas, sendo que o cirurgião-dentista desempenha um papel fundamental no manejo clínico do paciente infantil. É possível melhorar a qualidade de vida antes, durante e após as terapias antineoplásicas através de um protocolo de atendimento odontológico.

Precisa-se ter consciência de que a criança e seus familiares estão em um momento muito delicado de suas vidas, necessitando de muita dedicação e apoio das pessoas envolvidas em seu tratamento, sendo que todo o possível deve ser feito para que eles se sintam mais amparadas e confiantes para vencerem a batalha.

\section{REFERENNCIAS}

1 CABRERIZO,M.M.C.; ONATE,S.R.E.; GARCIA, B.C. Dental anomalies caused by Oncologycal treatment: case report. J Clin Pediatr Dent , v. 22, n.3, p.261-4, 1998.

2 CAIELLI, C.; MARTHA, P.M. Sequelas orais da radioterapia: atuação da odontologia na prevenção e tratamento. Rev Bras Cancerologia , v.41, n.4 , p.231-41, out., 1995.

3 CHIN, E.A. A brief overview of the oral complications in pediatric oncology patients and suggested management strategies. ASDC J Dent Child , v.65, n.6, p.468-73, nov., 1998.

4 CLAYMAN, L. Clinical controverses in oral and maxillofacial surgery: part two. Management of dental extractions in irradiated jaws: a protocol without hyperbaric oxygen therapy. J Oral Maxillofac Surg , v.55, n.3, p.27581, 1997.

5 DIB,L. L.; CURI, M.M. Manual de condutas diagnósticas e terapêuticas em odontologia. In:___ Complicações orais do tratamento oncológico, Brasil: Ambito Editores, p. 85-90. 1996.

6 DIB, L.L.; GONÇALVES,R.C.C.; KOWALSKI,L.P.; SALVAJOLI, J.V. Abordagem multidisciplinar das complicações orais da radioterapia. Rev Assoc Paul Cir Dentistas, v.54, n.5, p.391-96, setembro, 2000.

7 DOBBin, J. Leucemia Aguda. 2001. Disponível na Internet. http:// www.inca.gov.br/cancer/tipos/leucemia.html

8 DREINZEN, S. Tratamento das complicações orais da radioterapia do câncer. In: NEIDLE, E. A.; YAGIELA, J. A. Farmacologia e terapêutica para dentistas. $3^{\mathrm{a}}$ ed. Rio de Janeiro: Guanabara Koogan, 1991, cap.45, p.512-14.

9 FLEMING, P. Dental management of the pediatric oncology patient. Curr Opin Dent, v.1,n.5, p.577-82, oct.,1991.

10 FONSECA, M.A. Pediatric bone marrow transplantation: oral complications and recommendations for care. Pediatr Dent, v.20, n.7, p.386-94, 1998.

11 KARTHAUS M.; ROSENTHAL,C.; GANSER,A. Prophylaxis and treatment of chemo-and radiotherapy induced oral mucositis- are there new strategies? Bone Marrow Transplant , v.24, n.10, p. 1095-108, 1999.

12 LOPES,L.F.; CAMARGO, B.; BIANCHI,A. Os efeitos tardios do tratamento do câncer infantil. Rev Assoc Med Bras , v.46, n.3, jul-set., 2000. 
13 MAEDA, Y.C. Manifestações bucais da leucemia e do tratamento anti-neoplásico. Piracicaba, 1998. Monografia (Curso de Especialização em Odontopediatria), Universidade Estadual de Campinas.

14 MC KENNA, S.J. Leukemia. Oral Surg Oral Med Oral Pathol Oral Radiol Endod,v.89, n.2, p.137-9, 2000.

15 MINICUCCI, E. M.; DIB, L. L. Sequelas odontológicas do tratamento rádio e quimioterápico em crianças. Rev Paul Pediatria, v.12, n.2, p.258-63, julho, 1994.

16 MINISTÉRIO DA SAÚDE. O que é o câncer. ,2003. Disponível na Internet. http://www.inca.gov.br/cancer/o que é.

17 NATIONAL INSTITUTES OF HEALTH. Consensus development conference statement: oral complications of cancer therapies: diagnosis, prevention, and treatment. J Am Dent Assoc , v.119, n.1, p.179-83, 1989.

18 REY,E; MICHELET, M.C. Tratamiento de las complicaciones bucales en pacientes oncohematológicos, durante la granulocitopenia producida por la quimioterapia. Rev Fac Odontol , v.14. , n.35, p.70-6, abril, 1994.

19 RIBEIRO, K.C.B.; ESTEVES, A.R.F. Atuação odontológica na prevenção e tratamento de complicações orais da terapêutica oncológica em crianças. Acta Oncol Bras, v.17,n.1, p.29-32, mar., 1997.

20 ROBINS, S.L.; COTRAN,R.S.; KEEMAR,V. Patologia estrutural e funcional. 3.ed. Rio de Janeiro: Guanabara Koogan , 1986.

21 SHAFFER,W.G.; HENE,M.K.; LEVY,B.M. Tratado de patologia bucal. 4.ed. Rio de Janeiro : Guanabara Koogan, 1987. 837 p.

22 SILVERMAN S. Jr. Oral Cancer . 3 ed. Atlanta: The American Cancer Society, 1990.

23 SONIS,S.T.; FAZIO,R.C.; FANG,L. Princípios e prática de medicina oral. 2.ed. Rio de Janeiro : Guanabara Koogan, $1996.491 \mathrm{p}$. 